\title{
Glucose and Glycogen Metabolism in
}

\section{Erythrocytes from Normal and Glycogen}

\author{
Storage Disease Type III Subjects
}

\author{
Shimon W. Moses, Reuben Chayoth, Stanley Levin, Ela Lazarovitz, \\ and DAVID RUBINSTEIN
}

From the Department of Pediatric Research, Kaplan Hospital, Rehovoth, Israel

A в S TRACT Active glycogen metabolism has been demonstrated in both normal and glycogenrich erythrocytes taken from patients with type III glycogen storage disease. Activity of all enzymes catalyzing the reactions required for the synthesis and degradation of glycogen have been demonstrated in the mature erythrocytes. Uniformly labeled glucose- ${ }^{14} \mathrm{C}$ is incorporated into glycogen in intact cells of both types during incubation. Replacement of the glucose- ${ }^{14} \mathrm{C}$ by unlabeled glucose in the medium resulted in a significant loss of radioactivity from cellular glycogen. In the absence of the substrate a progressive shortening of outer branches occurred during incubation of intact glucogen-rich cells. Using cells from patients with type III glycogen storage disease, which have sufficient glycogen content to be analyzed by $\beta$-amylolysis, we demonstrated that the glucosyl units are first incorporated in the outer tiers, then transferred to the core where they tend to accumulate due to the absence of amylo-1,6-glucosidase.

The glycogen-rich cells have a more rapid rate of glucose utlization upon incubation which is not reflected by a higher lactate production. The increased rate of glucose utilization did not result

Dr. Moses' present address is Department of Pediatrics "B", Negev Central Hospital, Beer-Sheba, Israel. Dr. Rubinstein is a Medical Research Council of Canada Visiting Professor. His permanent address is the Department of Biochemistry, McGill University, Montreal, Canada.

Kaplan Hospital is affiliated with The Hebrew University Hadassah Medical School, Jerusalem, Israel.

Received for publication 20 November 1967 and in revised form 2 February 1968. from an increased rate of glucose incorporation into glycogen in affected cells. The rate of ${ }^{14} \mathrm{CO}_{2}$ production from glucose- $1-{ }^{14} \mathrm{C}$ during incubation was not significantly different in the two types of cells unless methylene blue was added as an electron acceptor, in which case the glycogen-rich cells oxidized glucose to $\mathrm{CO}_{2}$ more rapidly.

\section{INTRODUCTION}

The mature human erythrocyte meets its energy requirement primarily from the metabolism of carbohydrates, chiefly glucose, although other monosaccharides can be utilized (1). Normally $6-8 \mu$ moles of glucose per $\mathrm{g}$ of hemoglobin per $\mathrm{hr}$ are broken down to lactate via the EmbdenMeyerhof pathway (2). In addition a small fraction of the glucose-6-phosphate formed is metabolized via the hexosephosphate pathway yielding reduced nicotinamide adenine dinucleotide phosphate (3). In spite of its dependence upon glucose for energy production the normal red blood cell has virtually no carbohydrate stores, although there is a minimal concentration of glycogen (4-6). It was believed that this glycogen was not actively metabolized $(5,7)$ but was a vestigal remnant of an immature erythrocyte stage (5). Nevertheless as all enzymes catalyzing glycogen synthesis and breakdown have now been demonstrated in the erythrocyte (8-12) it would not be unexpected to find a functional glycogen pathway. However, the minute concentrations of glycogen in the erythrocyte have thus far precluded extensive studies of its metabolism. 
In type III glycogen storage disease (GSD) which is characterized by the absence of amylo1-6-glucosidase in various tissues, including the erythrocyte, there is an abnormally high erythrocyte concentration of glycogen of the limit dextrin type (5). The relatively high incidence of type III GSD in Israel (13) provided a supply of erythrocytes sufficiently high in glycogen content to make possible an investigation of glycogen metabolism. In addition, advantage was taken of the availability of these cells to compare their overall carbohydrate metabolism with those from normal donors. The results to be presented in this report indicate that there is an active turnover of glycogen in both normal and amylo-1,6-glucosidase-deficient cells. In addition it was observed that the glycogen-rich cells utilized glucose at a higher rate than normal cells.

\section{METHODS}

The subjects of this study were 17 patients in whom the diagnosis of type III GSD had been made on clinical, biochemical, and enzymatic bases. None of them had abnormal hemoglobin values or elevation of the reticulocyte count or bilirubin levels. In some of the GSD patients erythrocyte life span measured by ${ }^{51} \mathrm{Cr}$ labeling, osmotic fragility, and density distribution (14) was determined and all were found to be within normal limits. The glycogen concentration of these erythrocytes ranged from 200$3000 \mu \mathrm{g} / \mathrm{g}$ of hemoglobin with a mean of $1054 \mu \mathrm{g} / \mathrm{g}$ of hemoglobin (these levels are within the range previously reported by Sidbury, Cornblath, Fisher, and House [5] for GSD type III erythrocytes; normal range 20-134 $\mu \mathrm{g} / \mathrm{g}$ of hemoglobin). Normal control blood was obtained from physicians and laboratory personnel. The blood samples were drawn into heparinized plastic tubes and the erythrocytes sedimented by centrifugation in the cold. The plasma, buffy coat, and approximately $10 \%$ of the erythrocytes were removed by cutting the plastic tubes below the leukocyte-rich layer. With this technique virtually all reticulocytes, thrombocytes, and leukocytes were removed, leaving a thrombocyte count below 4000 and white blood cell count that approached zero in most experiments and was never more than 200 cells $/ \mathrm{mm}^{3}$. The erythrocytes were then washed three times with 10 volumes of cold $0.9 \% \mathrm{NaCl}$ before their use in the various studies.

Hemoglobin was measured as cyanmethemoglobin (15), deproteinization was performed with Somogyi reagents (16) for glucose determinations and with $6 \%$ trichloroacetic acid for analysis of lactates. Glucose was determined by the glucose oxidase method (17) and lactates were determined enzymatically by the method of Horn and Burns (18). Hexokinase activity was determined according to Valentine and Oski (19) and phosphoglucomutase by a modification of the method of Bergmeyer for glucose-1-phosphate determination (20).
Amylo-1,6-glucosidase and phosphorylase were determined according to the procedure of Hers (21) and uridine diphosphoglucose (UDPG) glycogen glucosyltransferase by the method described by Cornblath (8). $\alpha-1,4$ Glucan: $\alpha$-s-i,4 glucan 6 -glycosyltransferase was determined by a method described by Larner (22). Glycogen was recovered from erythrocytes after repeated precipitation of the protein with cold $6 \%$ trichloroacetic acid, collection of the supernatant, and precipitation of glycogen in cold $95 \%$ ethanol after the addition of $0.18 \% \mathrm{Na}_{2} \mathrm{SO}_{4}$ (23). Glycogen was determined with diazyme reagent (24).

For the determination of the incorporation of glucose $-{ }^{14} \mathrm{C}$ into glycogen the incubation mixture was removed after the incubation, nonlabeled carrier glycogen added, and the glycogen precipitated with cold trichloroacetic acid as described by Sidbury (5). Parallel incubations without erythrocytes revealed no nonspecific glucose-glycogen exchange. Analysis of the distribution of the glucose in the outer branches and inner core of the glycogen was carried out by $\beta$-amylolysis (25). The production of ${ }^{14} \mathrm{CO}_{2}$ from glucose was studied by incubating the erythrocytes with the appropriate reaction mixture in sealed vials equipped with center wells containing $0.5 \mathrm{ml}$ of $15 \% \mathrm{KOH}$ absorbed on No. 1 Whatman filter paper. After the incubation $0.4 \mathrm{ml}$ of $1 \mathrm{~N} \mathrm{H}_{2} \mathrm{SO}_{4}$ was injected into the incubation mixture and the vial shaken for 1 additional $\mathrm{hr}$. The ${ }^{14} \mathrm{C}$ absorbed on the filter paper was then counted. All radioactivity was assayed in a Tri-Carb liquid scintillation counter utilizing a gel for equal dispersion of the radioisotope (26).

Various coenzymes and adenosine triphosphate were obtained from Boehringer and Sons, Mannheim, Germany or Sigma Chemicals, St. Louis, Mo. Enzymes were obtained from Boehringer and Sons, diazyme from Miles Chemical Corporation, Elkhart, Ind.

\section{RESULTS}

The incorporation of glucose- $\mathrm{U}-{ }^{14} \mathrm{C}$ into glycogen in the erythrocytes from patients with type III GSD was first studied and found to be linear over a period of $3 \mathrm{hr}$. To further demonstrate the active metabolism of erythrocyte glycogen, red blood cells taken from both normal subjects and patients suffering from type III GSD were incubated for 2 hr with glucose-U- ${ }^{14} \mathrm{C}$. The results, shown in Table I, indicate that both types of erythrocytes incorporate glucose into glycogen at the same rate. Subsequently a portion of the cells was washed and reincubated in the same medium except that unlabeled glucose was present. This resulted in a disappearance of a major portion of the labeled glucosyl units of the glycogen from both types of cells (Table I). Further insight into the breakdown of glycogen was provided by incubating the glycogen-rich cells in the absence of 
TABLE I

Turnover of Glucose in Erythrocyte Glycogen

\begin{tabular}{|c|c|c|}
\hline & Normal (5) & $\begin{array}{l}\text { Type III } \\
\text { GSD (15) }\end{array}$ \\
\hline & \multicolumn{2}{|c|}{$\mu$ moles $/ \mathrm{g} H b \pm \mathrm{SEM}$} \\
\hline $\begin{array}{l}\text { Glucose-U-14C incorporation } \\
\text { after } 2 \mathrm{hr} \text { or incubation }\end{array}$ & $0.094 \pm 0.02$ & $0.017 \pm 0.02$ \\
\hline $\begin{array}{l}\text { Glucosyl-14C units remain- } \\
\text { ing in glycogen after ad- } \\
\text { ditional 2-hr incubation } \\
\text { with unlabeled glucose }\end{array}$ & $0.026 \pm 0.007$ & $0.014 \pm 0.003$ \\
\hline
\end{tabular}

Figures in parentheses represent number of cases. Incubation conditions: each flask contained a $20 \%$ cell suspension in an isotonic medium containing $0.25 \mu \mathrm{c}$ of $0.002 \mathrm{M}$ glucose-U-4 ${ }^{4} \mathrm{C}, 0.025 \mathrm{M} \mathrm{NaHPO}_{4}, 0.05 \mathrm{~m}$ glycylglycine buffer, $\mathrm{pH} 7.8$, and $\mathrm{NaCl}$ to make a total volume of $4 \mathrm{ml}$. Temperature: $37^{\circ} \mathrm{C}$; gas phase : air; incubation time: $2 \mathrm{hr}$. At the end of the first 2-hour period the cells were washed and reincubated for an additional $2 \mathrm{hr}$ in the same medium, except that unlabeled glucose replaced the glucose-U-14C.

substrate, extracting the glycogen at varying time intervals, and submitting it to $\beta$-amylolysis. The results, shown in Fig. 1, indicate that there is a shortening of the length of the outer brances as the breakdown of glycogen proceeds over the $3 \mathrm{hr}$ period.

Experiments were performed to determine whether the incorporation of glucose into glycogen results only in a lengthening of outer branches of the glycogen molecule or also involves the new formation of an inner core. $\beta$-amylolysis was performed on glycogen taken at regular intervals from the glycogen-rich cells which had been allowed to incorporate glucose- $\mathrm{U}-{ }^{14} \mathrm{C}$ for periods up to $3 \mathrm{hr}$. The results are shown in Table II. While incorporation of glucose continued throughout the incu-

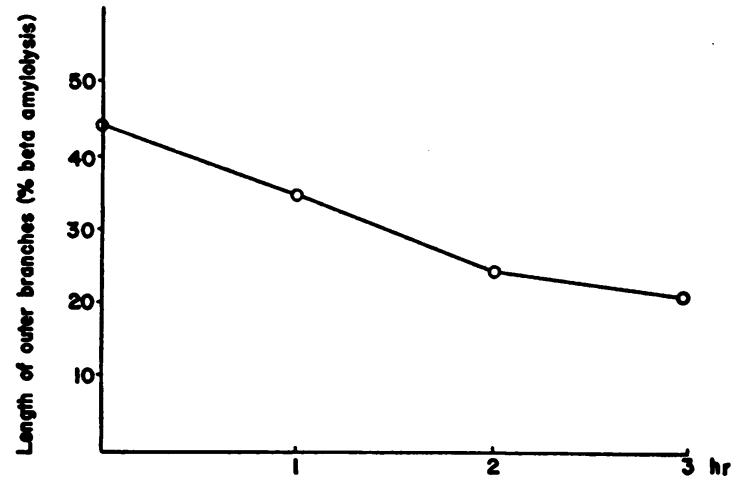

FIGURE 1 Rate of glycogen breakdown in intact erythrocytes of type III GSD: shortening of outer branches during incubation. Conditions as in Table I except that glucose was omitted.
TABLE II

Shift of Radioactivity from Outer Tiers to Inner Core of Glycogen in Type III GSD Erythrocytes Previously Labeled with Glucose- $U-{ }^{14} \mathrm{C}$ In Vitro

\begin{tabular}{|c|c|c|}
\hline Time & $\begin{array}{l}\text { Glucose incor- } \\
\text { poration into } \\
\text { glycogen }\end{array}$ & Inner core \\
\hline $\min$ & $\begin{array}{c}\text { यmoles of } \\
\text { glucose } / \mathrm{g} \mathrm{Hb}\end{array}$ & $\begin{array}{l}\% \text { of total } \\
\text { radioactivity }\end{array}$ \\
\hline 30 & 0.034 & 12.5 \\
\hline 60 & 0.042 & 48.5 \\
\hline 90 & 0.058 & 63.0 \\
\hline 120 & 0.077 & 87.2 \\
\hline 180 & 0.105 & 87.6 \\
\hline
\end{tabular}

Incubation conditions: as in Table I.

bation period a shift of labeled glucosyl units from the periphery was reflected by the increasing percentage of radioactivity found in the limit dextrin fraction of the glycogen as the experiment progressed.

The activities of the various enzymes involved in glycogen metabolism were compared in normal and glycogen-rich erythrocytes. The data presented in Table III indicate that, as expected, there was virtually no amylo-1,6-glucosidase activity in any of the cells from subjects suffering from type III GSD. No difference was noted in the activities of hexokinase, phosphoglucomutase, UDPG glycogen glucosyltransferase or $\alpha-1,4$ glucan : $\alpha-1,4$ glucan 6 -glycosyltransferase (branching enzyme). However, a significant increase in activity of phosphorylase was found in the erythrocytes from patients suffering from type III GSD.

The rates of glucose utilization and lactate production in normal and glycogen-rich cells were compared. The results, shown in Table IV indicate that the rate of glucose utilization by erythrocytes from patients suffering from type III GSD is significantly greater than that seen with the normal erythrocytes. The relatively higher rate of glucose utilization by the glycogen-rich cells occurred at medium inorganic phosphate levels ranginf from 3-50 mmoles/liter although the difference was more striking at higher phosphate concentrations. ${ }^{1}$ However, the increased glucose utilized is not recovered as lactate, which is similar in the two types of cells and in the normal erythrocyte accounts for about $85 \%$ of the glucose utilized.

1 Moses, S., and R. Chayoth. Unpublished observations. 
TABLE III

Activities of Enzymes Concerned with Glycogen Metabolism in Erythrocytes from Normal and Type III GSD Subjects

\begin{tabular}{|c|c|c|c|c|c|c|c|c|c|}
\hline \multirow{2}{*}{$\begin{array}{ll} & \text { Enzyme } \\
\text { Hexokinase } & \end{array}$} & \multirow{2}{*}{$\frac{\text { Units, } \pm \text { SEM }}{\text { Wroblewsky } \mathrm{U}^{*} / \mathrm{g} \mathrm{Hb}}$} & \multicolumn{3}{|c|}{ Normal } & \multicolumn{4}{|c|}{ Type III GSD } & \multirow{2}{*}{$\begin{array}{c}P \\
\text { NS }\end{array}$} \\
\hline & & 1598 & \pm 24 & (4) & 1702 & \pm 2 & & (4) & \\
\hline Phosphoglucomutase & Wroblewsky U/g Hb & 1086 & \pm 74 & (4) & 1150 & \pm 10 & & (4) & NS \\
\hline $\begin{array}{l}\text { Amylo-1,6-glucosidase (debrancher } \\
\text { enzyme) }\end{array}$ & $\begin{array}{l}\% \text { glucose incorporated } / \mathrm{g} \\
\text { Hb per hr }\end{array}$ & 0.2 & \pm 0.04 & (13) & $0.004=$ & \pm & 0.002 & (8) & $<0.005$ \\
\hline Phosphorylase & $\begin{array}{l}\mu \text { mole } \mathrm{PO}_{4} \text { released } / \mathrm{g} \\
\mathrm{Hb} \text { per } \mathrm{hr}\end{array}$ & 5.9 & \pm 1.2 & (9) & 9.7 & \pm & 1.7 & (8) & $<0.01$ \\
\hline UDPG glycogen glucosyltransferase & $\begin{array}{l}\mu \text { mole glucose incorporated } \\
\text { into glycogen }\end{array}$ & 1.7 & \pm 0.16 & (7) & 1.95 & \pm & 0.24 & (4) & NS \\
\hline $\begin{array}{l}\alpha-1,4 \text { Glucan : } \alpha-1,4 \text { glucan } 6 \text { glycosyl- } \\
\text { transferase (brancher enzyme) }\end{array}$ & Units $\ddagger / g \mathrm{Hb}$ & 8.3 & \pm & (3) & 10.3 & \pm & & (3) & \\
\hline
\end{tabular}

Figures in parentheses represent number of cases; NS, not significant.

* Vide Bergmeyer (20).

$\ddagger 1 \mathrm{U}=$ change in $\mathrm{OD}$ of $0.001 / \mathrm{min}$ at $520 \mathrm{~m} \mu$.

The possibility that the increased glucose utilization noted in the glycogen-rich erythrocyte might reflect an increase in the oxidation of glucose via the hexose monophosphate shunt was investigated in the presence and absence of methylene blue. Production of ${ }^{14} \mathrm{CO}_{2}$ from glucose- $1-{ }^{14} \mathrm{C}$ was used as an indication of shunt activity. The results shown in Table $\mathrm{V}$, indicate that ${ }^{14} \mathrm{CO}_{2}$ production by cells from the type III GSD patients is significantly greater than controls when methylene blue is added. Even in the absence of the electron acceptor there is an indication that the rate of ${ }^{14} \mathrm{CO}_{2}$ is higher in the glycogen-rich cells although the difference is not statistically significant.

\section{DISCUSSION}

The evidence accumulated in this report leaves no doubt that the erythrocyte maintains an active glycogen metabolism. It has been demonstrated that the glucose $-{ }^{14} \mathrm{C}$ is both incorporated into and

\section{TABLE IV}

Glucose Utilization and Lactate Production by Erythrocytes from Normal and Type III GSD Subjects during Incubation at $37^{\circ} \mathrm{C}$

\begin{tabular}{|c|c|c|c|}
\hline & Normal & Type III GSD & $P$ \\
\hline \multicolumn{4}{|c|}{$\mu$ moles $/ g$ Hb per $h r \pm \mathrm{SEM}$} \\
\hline Glucose utilized & $7.5 \pm 0.34(58)$ & $10.9 \pm 0.86(10)$ & $<0.0001$ \\
\hline Lactate produced & $12.8 \pm 0.62(26)$ & $11.8 \pm 0.82$ & NS \\
\hline
\end{tabular}

Figures in parentheses represent number of experiments (conducted with blood from 12 patients). Incubation conditions: as in Table I except that a $10 \%$ erythrocyte suspension and unlabeled glucose was used. Aliquots of the incubation mixture were assayed hourly and the values above represent the hourly average. released from glycogen, that redistribution of the glycosyl units within the glycogen molecule occurs, and that the outer branches are shortened after periods of incubation in the absence of added glucose. Since leukocytes, thrombocytes, and reticulocytes have been virtually removed from the erythrocyte preparations before use, the glycogen metabolism must be attributed to the mature human erythrocytes whether taken from normal or type III GSD subjects. Thus the concept that the mature erythrocyte has no active glycogen metabolism is no longer tenable. This is not surprising in view of the demonstration that all of the enzymes concerned with glycogen synthesis and breakdown are present in the normal erythrocyte. It could be argued that the observed incorporation of glucose into glycogen is due to an exchange reaction catalyzed by amylo-1,6-glucosidase. Since this incorporation has been shown to occur also in amylo-1,6-glucosidase-deficient cells this possibility can be ruled out. The question whether incorporation of radioactive glucose into glycogen occurs

\section{TABLE V}

${ }^{14} \mathrm{CO}_{2}$ Production from Glucose-1-14 $\mathrm{C}$ by Erythrocytes from Normal and Type III GSD Subjects

\begin{tabular}{|c|c|c|c|}
\hline & Normal & Type III GSD & $P$ \\
\hline & \multicolumn{2}{|c|}{$\mu$ moles $/ \mathrm{g} H b$ per $h r \pm \mathrm{SE}$} & \\
\hline Control & $0.074 \pm 0.008(8)$ & $0.10 \pm 0.012(14)$ & NS \\
\hline Methylene blue, $0.01 \%$ & $2.28 \pm 0.26$ & $3.60 \pm 0.27$ & $<0.01$ \\
\hline
\end{tabular}

Figures in parentheses represent number of subjects. Incubation conditions: as in Table I except that $0.5 \mathrm{ml}$ of $15 \% \mathrm{KOH}$ was placed in center well of the flasks and $0.15 \mu \mathrm{c}$ of glucose-1-14C was added. 
via the UDPG glycogen synthetase pathway or is caused by a reversal of the phosphorylase reaction is irrelevant, since in both instances active glycogen metabolism would result. However, in view of the presence of glycogen synthetase and the fact that UDPG is formed in erythrocytes, e.g., in the metabolism of galactose, it seems likely that the synthetase-catalyzed pathway is utilized in the erythrocytes.

Whereas glycogen synthesis occurs normally in amylo-1,6-glucosidase-deficient cells, breakdown cannot proceed beyond the branch point and is, therefore, limited to peripheral tiers only. Thus the observed decrease in radioactivity of the peripheral tiers and concomitant increase in activity of the central core as a function of time during incubation of the glycogen-rich erythrocytes with glucose- $\mathrm{U}-{ }^{14} \mathrm{C}$ can be readily explained as follows: there is an elongation of peripheral tiers which, after attaining a certain length normally form new branches. Since during glycogenolysis hydrolysis cannot proceed beyond the branch points in view of the absence of amylo-1,6-glucosidase, radioactive glucosyl units will be trapped in the inner core. This also explains the increased accumulation of the limit dextrin type glycogen in the cells from patients with type III GSD. Because of the small amount of glycogen present in normal erythrocytes it was not possible to carry out similar studies of the distribution and rearrangement of labeled glucosyl units with time in these cells.

The finding that the glycogen-rich cells utilized glucose at a greater rate than normal erythrocytes was surprising, especially since the rate of incorporation of glucose into glycogen did not differ between the two types of cells. Since the excess glucose utilized by the glycogen-rich cells does not appear as lactate, the carbon atoms must be trapped in some other glycolytic intermediate. The increase in oxidation of glucose to $\mathrm{CO}_{2}$ by the diseased cells even if significant is inadequate to account for the excess glucose disappearance.

It is evident from these studies that the metabolic abnormalities encountered in erythrocytes of patients with type III GSD are not restricted to abnormal glycogen accumulation but involve alterations of carbohydrate metabolism including active glycogen turnover and in the metabalic controls of glucose utilization at a level still to be determined.

\section{ACKNOWLEDGMENT}

This paper was supported by a research grant of the National Institute of Health, No. AM-09-302-03.

\section{REFERENCES}

1. Bishop, C. 1964. Overall red cell metabolism. In The Red Blood Cell; A Comprehensive Treatise. C. Bishop and D. M. Surgenor, editors. Academic Press, Inc., New York. 161.

2. Tsuboi, K. K. 1965. Limiting role of adenine nucleotide in the glycolysis of the human erythrocyte. $J$. Biol. Chem. 240: 582.

3. Murphy, J. R. 1960. Erythrocyte metabolism. II. Glucose metabolism and pathways. J. Lab. Clin. Med. 55: 286.

4. Wagner, R. 1946. The estimation of glycogen in whole blood and white blood cells. Arch. Biochem. Biophys. 11: 249.

5. Sidbury, J. B., Jr., M. Cornblath, J. Fisher, and E. House. 1961. Glycogen in erythrocytes of patients with glycogen storage disease. Pediatrics. 27: 103.

6. Sidbury, J. B., Jr., R. Gitzelman, and J. Fisher. 1961. The glycogenoses: further observations on glycogen in erythrocytes of patients with glycogenosis. Helv. Paediat. Acta. 16: 506.

7. Crevasse, L., W. H. Hezson, G. G. Hasouri, and J. C. Shipp. 1965. Glucose metabolism of red blood cells. A study of triiodothyronine on red cell metabolism. J. Lab. Clin. Med. 65: 539.

8. Cornblath, M., D. F. Steiner, P. Bryan, and J. King. 1965. Uridine diphosphoglucose glucosyltransferase in human erythrocytes. Clin. Chim. Acta. 12: 27.

9. Cornblath, M., E. Y. Levin, E. Marquetti, and E. Y. House. 1960. Phosphorylase activity in human erythrocytes. Federation Proc. 19: 68.

10. Chayoth, R., S. W. Moses, and K. Steinitz. 1967. Debrancher enzyme activity in blood cells of families with type III glycogen storage disease: a method for diagnosis of heterozygotes. Israel J. Med. Sci. 3: 422.

11. Kalckar, H. M., and E. S. Maxwell. 1958. Biosynthesis and metabolic functions of uridine diphosphoglucose in mammalian organisms and its relevance to certain inborn errors. Physiol. Rev. 38: 77.

12. Noltman, E., and F. H. Bruns. 1958. Uber die Phosphoglucomutase der Erythrocyten und des Serums. Z. Physiol. Chem. 313: 194.

13. Levin, S., S. W. Moses, R. Chayoth, N. Jagoda, and K. Steinitz. 1967. Glycogen storage disease in Israel. A clinical biochemical and genetic study. Israel $J$. Med. Sci. 3: 397.

14. Danon, D., and Y. Marikovsky. 1964. Determination of density distribution of red cell population. J. Lab. Clin. Med. 64: 668.

15. Cartwright, C. E. 1963. Diagnostic Laboratory Hematology. Grune and Stratton Inc., New York. 3rd edition. 42.

16. Somogyi, M. 1945. The determination of blood sugar. J. Biol. Chem. 160: 69. 
17. Kingsley, C. R., and G. Getchele. 1960. Direct ultramicro glucose oxidase for the determination of glucose in biological fluids. Clin. Chem. 6: 644.

18. Horn, H. D., and F. H. Bruns. 1956. Quantitative Bestimmung von $\mathrm{L}(+)$-Milchsaure mit Milchsaure Dehydrogenase. Biochim. Biophys. Acta. 21 : 378.

19. Valentine, W. N., F. A. Oski, D. E. Paglia, M. A. Baughan, A. S. Schneider, and J. L. Naiman. 1967. Hereditary hemolytic anemia with hexokinase deficiency. New Engl. J. Med. 271: 1.

20. Bergmeyer, H. U. 1965. Methods of Enzymatic Analysis. Verlag Chemis. Weinheim. 1st edition. 131.

21. Hers, H. G. 1963. $\alpha$-Glucosidase deficiency in generalized glycogen storage disease (Pompe's disease). Biochem. J. 86: 11.
22. Larner, J. 1955. Branching enzyme from liver, amylo1,4-1,6-transglucosidase. In Methods in Enzymology. S. P. Colowick and N. O. Kaplan, editors. Academic Press, Inc., New York. 1: 222.

23. Van Handel, E. 1965. Estimation of glycogen in small amounts of tissue. Anal. Biochem. 11: 256.

24. Johnson, J. A., J. D. Nash, and R. M. Fusaro. 1963. An enzymic method for the quantitative determination of glycogen. Anal. Biochem. 5: 379.

25. Steinitz, K. 1967. Laboratory diagnosis of glycogen diseases. Advan. Clin. Chem. 9: 227.

26. Ott, D. G., C. R. Richmond, T. T. Trujillo, and H. Foreman. 1959. Cab-O-Sil suspensions for liquid scintillation counting. Nucleonics. 17: 106. 